\title{
ANÁLISE DO CONTEÚDO DE BOTÂNICA NOS LIVROS DIDÁTICOS DO ENSINO FUNDAMENTAL
}

\author{
NAYARA CAMPOS DA CUNHA ${ }^{1}$ \\ JULIANA DE LIMA PASSOS REZENDE ${ }^{2}$ \\ IZABELLA SCALABRINI SARAIVA ${ }^{3}$
}

\begin{abstract}
RESUMO: Estudos anteriores vêm relatando a dificuldade no ensino de Botânica por professores de Ciências, logo, torna-se necessário o uso de materiais para auxiliá-los no ensino deste conteúdo. Tendo em vista que o livro didático é o principal recurso pedagógico utilizado nas escolas da rede pública, acredita-se que este tenha papel relevante na melhoria desse ensino. Dessa forma, a presente pesquisa se propôs a analisar o conteúdo de Botânica em quatro livros didáticos do 70 ano a partir de critérios fundamentados pelo referencial na área e contextualizados com a realidade deste ensino. Foram encontrados erros conceituais, desatualização e simplificações em parte dos livros. Entretanto, se bem escolhido, o livro didático pode auxiliar nas melhorias nesse ensino a partir de seus conteúdos e de suas diversas práticas e exercícios complementares, permitindo que o educando se aproxime mais do reino vegetal e veja as diversas utilidades da Botânica em seu cotidiano.

Palavras chave: Ensino de Botânica. Livro didático. Ensino Fundamental.
\end{abstract}

\section{ANALYSIS OF THE BOTANICAL CONTENT IN THE TEACHING BOOKS OF ELEMENTARY $S C H O O L$}

ABSTRACT: Previous studies have reported the difficulty in teaching botany by science teachers, so it becomes necessary to use materials to assist them in teaching this content. Considering that the textbook is the main pedagogical resource used in schools of the public network, it is believed that this one has a relevant role in the improvement of this teaching. In this way, the present research proposed to analyze the content of Botany in four textbooks of the 7th year based on criteria based on the referential in the area and contextualized with the reality of this teaching. Conceptual errors, outdatedness, and simplifications were found in part of the books. However, if chosen, the textbook can help improve this teaching from its contents and its various practices and complementary exercises, allowing the learner to come closer to the plant kingdom and see the various uses of botany in their daily life.

Keywords: Teaching Botany. Science textbook. Fundamental teaching.

1 Graduada em Ciências Biológicas PUC MG.

2 Mestre em Ecologia pela UFMG, professora e coordenadora de extensão da PUC MG/Betim.

3 Mestre em Biologia Vegetal pela UFMG, professora e coordenadora do Curso de Ciências Biológicas da PUC MG/Betim. 


\section{ANÁLISIS DEL CONTENIDO DE BOTÁNICA EN LOS LIBROS DIDÁCTICOS DE LA EDUCACIÓN BÁSICA}

RESUMEN: Estudios anteriores relatan la dificultad en la enseñanza de Botánica por profesores de Ciencias, luego, se hace necesario el uso de materiales para auxiliarlos en la enseñanza de este contenido. En vista de que el libro didáctico es el principal recurso pedagógico utilizado en las escuelas de la red pública, se cree que éste tiene un papel relevante en la mejora de esta enseñanza. Así, la presente investigación se propuso analizar el contenido de Botánica en cuatro libros didácticos del 7으o año a partir de criterios fundamentados por el referencial en el área y contextualizados con la realidad de esta enseñanza. Se encontraron errores conceptuales, desactualización y simplificaciones en parte de los libros. Sin embargo, si bien escogido, el libro didáctico puede auxiliar en las mejoras en esta enseñanza a partir de sus contenidos y de sus diversas prácticas y ejercicios complementarios, permitiendo que el educando se aproxime más del reino vegetal y vea las diversas utilidades de la Botánica en su cotidiano.

Palabras clave: Enseñanza de Botánica. Libro didáctico. Educación básica.

\section{Introdução}

A preocupação com a qualidade dos livros didáticos no Brasil está presente desde o século passado. Em 1938, por meio do Decreto-Lei no 1.006 de 30/12/38, foi instituída a Comissão Nacional do Livro Didático, que tinha como objetivo estabelecer políticas de legislação e controle de produção e circulação do livro didático no País (BRASIL, 2017). Atualmente, o material passa por diversas avaliações para constatar se as obras inscritas se enquadram nas exigências técnicas e físicas. Os livros selecionados são encaminhados à Secretaria de Educação Básica (SEB/MEC), que é responsável por escolher os especialistas para analisar as obras. Esses especialistas elaboram as resenhas dos livros aprovados que passam a compor o Guia do Livro Didático (GLD), que orienta os profissionais da educação na escolha dos livros a serem adotados pelas escolas.

Os principais pontos analisados nas obras são: erros conceituais, indução a erros, desatualização, preconceito ou discriminação de qualquer tipo. A não adequação a qualquer um desses itens pode acarretar na exclusão da obra do processo de seleção (TATARA; LISOVSKI, 2011). Posteriormente, o Fundo Nacional de Desenvolvimento da Educação (FNDE) disponibiliza o guia em seu portal na internet e envia o mesmo material impresso às escolas cadastradas no censo escolar.

Apesar da gama de profissionais envolvidos nesse ofício de avaliação dos livros didáticos, diversos trabalhos afirmam a presença de erros no conteúdo destes materiais. Segundo Carneiro, Santos e Mól (2005), alguns aspectos têm ficado à margem desses estudos como, por exemplo, a análise da proposta metodológica, as relações entre esse recurso de ensino e as práticas pedagógicas do professor e, finalmente, há ainda poucos estudos sobre suas diferentes formas de uso no contexto 
escolar.

“A profissão de professor não se define mais pela transmissão de conhecimento, mas pela reconstrução do conhecimento" (DEMO, 2005). O livro didático deve auxiliá-lo nessa função, promovendo em seus conteúdos, práticas e pesquisas em junção de textos externos que abordem temas atuais, além da descrição de metodologias didáticas para tais atividades.

No livro "Educar pela pesquisa" (DEMO, 2005) frisa a importância de metodologias diferenciadas para a educação:

O recurso e as motivações lúdicas podem ser muito eficazes nos alunos, como a organização de feiras, gincanas, jogos, brincadeiras, competições, tomados todos como expedientes instigadores da capacidade de iniciativa e de formulação própria, sem falar no trabalho de equipe, sem exacerbar o horizonte competitivo, porquanto o desafio é educativo, é possível arquitetar nos alunos um ambiente investigador, aproveitando a potencialidade criativa que o lúdico naturalmente contém (DEMO, 2005, p. 30).

Entendemos assim, que o livro didático não deve ser utilizado como uma "bíblia" do ensino. Existem diversos recursos didáticos que podem ser utilizados para auxiliar nas aulas, como: vídeos, revistas, sites, entre outros. Porém, segundo Vasconcelos e Souto (2003), em consequência da realidade das condições existentes em muitas escolas do país, o livro didático tem sido praticamente o único instrumento auxiliar da atividade de ensino.

Como grande parte dos conteúdos biológicos explorados no Ensino Básico, o ensino em Botânica é marcado por diversos problemas e tem sido alvo de preocupação de vários pesquisadores. Silva e Lopes (2014), após uma análise de questionário aplicado com professores de ciências sobre o conteúdo de Biologia Vegetal, identificou que eles se sentem desconfortáveis em trabalhar temas de Botânica por não possuírem segurança no assunto. Melo et al. (2012) dizem que despertar nos alunos o interesse pela Botânica é um desafio em algumas salas de aula. Torna-se notória a necessidade da inclusão de metodologias diferenciadas para o ensino de Botânica e, os livros didáticos devem ser aptos a servir de apoio para o desenvolvimento de atividades nesta área. Assim, o presente trabalho avaliou, qualitativamente, o conteúdo de Botânica em quatro livros didáticos do 70 ano do ensino fundamental utilizados em escolas da rede pública do município de Betim, MG.

\section{Materiais e método}

Para esta pesquisa foram selecionados quatro livros didáticos do professor, referentes ao 
conteúdo de ciências do 70 ano do Ensino Fundamental que foram aprovados pelo PNLD de 2017 e que atualmente são utilizados em quatro escolas da rede municipal neste mesmo ano, no município de Betim, Estado de Minas Gerais. Esses livros estão apresentados no Quadro 1.

Quadro 1 - Identificação das obras analisadas no estudo

\begin{tabular}{|c|c|c|c|c|}
\hline $\begin{array}{c}\text { IDENTIFICAÇÃO } \\
\text { DA OBRA }\end{array}$ & LIVRO & AUTOR & EDITORA & $\begin{array}{c}\text { DATA DE } \\
\text { PUBLICAÇÃ̃o }\end{array}$ \\
\hline Livro A & $\begin{array}{c}\text { Ciências Novo } \\
\text { Pensar }\end{array}$ & $\begin{array}{c}\text { Demétrio Gowdak e } \\
\text { Eduardo Martins }\end{array}$ & FTD & 2015 \\
\hline Livro B & $\begin{array}{c}\text { Para Viver Juntos: } \\
\text { Ciências da } \\
\text { Natureza }\end{array}$ & $\begin{array}{c}\text { Lia Monguilhott Bezerra } \\
\text { e João Batista Aguillar }\end{array}$ & SM & 2015 \\
\hline Livro C & Ciências & $\begin{array}{c}\text { Carlos Barros e Wilson } \\
\text { Paulino }\end{array}$ & Ática & 2015 \\
\hline Livro D & $\begin{array}{c}\text { Ciências - Projeto } \\
\text { Teláris }\end{array}$ & $\begin{array}{c}\text { Fernando } \\
\text { Gewandsznajder }\end{array}$ & Ática & 2015 \\
\hline
\end{tabular}

Fonte: Dados da Pesquisa.

Para facilitar a avaliação de cada um dos livros, foi estabelecida uma categorização a partir de letras do alfabeto (A, B, C e D), como é possível observar no Quadro 01. Os parâmetros utilizados nesta pesquisa foram estabelecidos a partir dos critérios do componente curricular Ciências da Natureza, avaliados no Guia do Livro Didático (2017) e contextualizados com a realidade de ensino e as necessidades do professor. Durante uma pré-leitura das obras trabalhadas, observou-se a necessidade de inserção de algumas outras características para atender todos os aspectos dos livros, conforme mostra o Quadro 02. Os critérios escolhidos também foram inspirados nas categorias propostas por Bandeira, Stange e Santos (2012) no qual foram selecionadas: "a) Conteúdos - aspectos Teórico-metodológicos; b) Recursos Visuais; c) Atividades - aspectos Pedagógico-metodológicos;" Na categoria Atividades - aspectos pedagógicos-metodológicos, foram utilizadas três subunidades: "Práticas", "Questões e Exercícios" e "Conhecimento extra", a fim de ser específico ao conteúdo avaliado neste trabalho. Dessa forma, a presente pesquisa foi organizada em 5 categorias, totalizando 26 critérios de avaliação, vide Quadro 2 . 
Quadro 2 - Critérios a serem avaliados nos livros didáticos do professor

\begin{tabular}{|c|c|}
\hline & Critérios \\
\hline \multirow{6}{*}{ Conteúdos } & Clareza conceitual \\
\hline & Generalização \\
\hline & Coerência \\
\hline & Simplificações \\
\hline & Adequação ao ano escolar \\
\hline & Atualização de termos \\
\hline \multirow{4}{*}{ Recursos Visuais } & Ordenação sistemática \\
\hline & Contextualização \\
\hline & Organização \\
\hline & Fotos, Figuras e Esquemas \\
\hline \multirow{4}{*}{ Práticas } & Práticas dentro do meio escolar \\
\hline & Práticas fora do ambiente escolar \\
\hline & Percepção da Botânica no cotidiano \\
\hline & Resultados e auxílio na condução do experimento \\
\hline \multirow{6}{*}{$\begin{array}{l}\text { Questões e } \\
\text { Exercícios }\end{array}$} & Relação com o conteúdo apresentado \\
\hline & Estímulo à aplicação contextualizada com o ambiente \\
\hline & $\begin{array}{c}\text { Problematização com pesquisas ou questões ambientais voltados à } \\
\text { Botânica (desmatamento, queimadas e outros) }\end{array}$ \\
\hline & Contextualização com o cotidiano \\
\hline & Respostas no livro do professor \\
\hline & Presença de questões relacionadas a conteúdos extras \\
\hline \multirow{6}{*}{$\begin{array}{l}\text { Conhecimento } \\
\text { Extra }\end{array}$} & Etnobotânica e plantas medicinais \\
\hline & Plantas alimentícias \\
\hline & Uso de plantas em cosméticos e farmacologia \\
\hline & Paleobotânica \\
\hline & Mídias extras sobre Botânica (sites, livros, músicas...) \\
\hline & Estudos científicos na Botânica \\
\hline
\end{tabular}

Fonte: Dados da Pesquisa.

No critério de avaliação "Conteúdos", a revisão foi feita a partir do livro "Biologia Vegetal" de Raven, Evert e Eichhorn (2014), que é considerado um dos livros mais renomados na área da Botânica. As principais características avaliadas dentro dos conteúdos do livro didático foram: a clareza conceitual, não permitindo que os temas gerassem má interpretação entre os assuntos; as 
simplificações, que poderiam deixar o conteúdo raso e inconsistente; a generalização de termos ou conteúdos; coerência entre os textos e assuntos abordados no capítulo; adequação ao ano escolar, permitindo a interpretação dos textos do livro pelo grau de aprendizagem do aluno e; atualização do conteúdo, destacando os termos que não são mais utilizados e as referências para construção do texto apresentado.

No critério "Visual", as principais características trabalhadas foram voltadas à organização das informações, tais como padrão de formatação, cores, disposições dos textos; em imagens avaliouse a presença de escalas, referências, a nitidez das imagens, a contextualização com o conteúdo e a disposição nele; sistematização do conteúdo, se o conteúdo segue uma ordem lógica junto com seus textos complementares e imagens. Para o critério "Práticas", levou-se em consideração a presença de práticas possíveis de serem ministradas dentro ou fora do contexto escolar; o auxílio que o livro do professor dava na execução das mesmas, como conter resultados e expectativas para cada passo do experimento e se elas estimulam na percepção da Botânica no dia a dia.

Para avaliação do critério "Questões e Exercícios", observou-se a relação com os conteúdos de cada capítulo, se estimulavam a releitura ou confirmação da aprendizagem referente ao conteúdo trabalhado; estímulo à aplicação da Botânica contextualizada com o ambiente e outros seres vivos; problematização com pesquisas ou questões ambientais que se relacionam com a Botânica (como desmatamento, queimadas, transgênicos, inseticidas etc.); contextualização com a Botânica no dia a dia, como conhecer e diferenciar as partes dos alimentos de origem vegetal; observar as plantas ao redor da escola ou no caminho para a escola, entre outros; respostas das atividades no livro do professor; presença de questões relacionadas a conteúdos extras, como textos complementares ou atividades online em sites. E, finalmente, na avaliação dos conteúdos de "Conhecimento Complementar", os critérios a serem avaliados são: a Etnobotânica e plantas medicinais; plantas alimentícias e contextualização com o dia a dia; uso de plantas em cosméticos e farmacologia e contextualização; paleobotânica e a origem de grupos das plantas; mídias extras sobre Botânica (sites, livros, músicas...) e estudos científicos na Botânica.

A avaliação foi feita de forma qualitativa a partir dos conceitos da escala semântica. Segundo Lopes et al. (2011), "as escalas semânticas têm em cada extremo dois adjetivos opostos, por meio dos quais, os sujeitos avaliam o conceito, colocando uma marca na posição que mais se aproxima de seus sentimentos". Desse modo, foram escolhidos quatro pontos a serem avaliados separados nos seguintes termos: "ruim", "regular", "bom" e "ótimo"; como representado no esquema do Quadro 3. 
Quadro 3 - Escala semântica dos critérios da análise qualitativa

\begin{tabular}{|c|c|}
\hline $\begin{array}{c}\text { CONCEITOS DA } \\
\text { ESCALA SEMÂNTICA }\end{array}$ & PONDERAÇÃO AO CONCEITO \\
\hline Ruim & Ausência do critério avaliado. \\
\hline Regular & $\begin{array}{r}\text { Critério a ser avaliado está presente, porém de maneira inadequada, } \\
\text { necessitando de interferências para ser trabalhado. }\end{array}$ \\
\hline Bom & $\begin{array}{r}\text { Critério avaliado atende a maior parte das expectativas de forma } \\
\text { adequada, porém com ressalvas. }\end{array}$ \\
\hline Ótimo & Critério avaliado atende a todas as expectativas, sem ressalvas. \\
\hline
\end{tabular}

Fonte: Dados da Pesquisa.

Os pontos foram atribuídos por meio de marcação de " $\mathrm{X}$ " em cada um dos conceitos de acordo com a avaliação. No final, foi feito um somatório do número de marcações feitas nos conceitos e retirou-se a média pelo total de critérios, apresentando-se em porcentagem o resultado de cada livro avaliado.

\section{Resultados e discussão}

A partir da análise dos dados feita por leitura minuciosa dos capítulos referentes ao conteúdo de biologia vegetal, os resultados obtidos são expressos nos quadros de avaliação (Quadros 04 a 07). Em todos os livros foi observada a seguinte sequência de conteúdos no Reino Vegetal: briófitas, pteridófitas, gimnospermas e angiospermas (órgãos vegetativos: raiz, caule, folha; órgãos reprodutivos: flor, fruto, semente). 
Quadro 4 - Avaliação do livro didático Ciências Novo Pensar (2015) - Livro A

\begin{tabular}{|c|c|c|c|c|c|}
\hline \multicolumn{2}{|r|}{ Critérios } & Ruim & Regular & Bom & Ótimo \\
\hline \multirow{6}{*}{ Conteúdos } & Clareza conceitual & & & $\mathrm{x}$ & \\
\hline & Generalização & & & $\mathrm{x}$ & \\
\hline & Coerência & & & & $\mathrm{x}$ \\
\hline & Simplificações & & $x$ & & \\
\hline & Adequação ao ano escolar & & & & $\mathrm{x}$ \\
\hline & Atualização de termos & & $\mathrm{x}$ & & \\
\hline \multirow{4}{*}{ Visual } & Ordenação sistemática & & & & $x$ \\
\hline & Contextualização & & & & $\mathrm{x}$ \\
\hline & Organização & & & & $\mathrm{x}$ \\
\hline & Fotos, Figuras e Esquemas & & & & $\mathrm{x}$ \\
\hline \multirow{4}{*}{ Práticas } & Práticas dentro do meio escolar & & & & $\mathrm{x}$ \\
\hline & Práticas fora do ambiente escolar & & & & $\mathrm{x}$ \\
\hline & Percepção da Botânica no cotidiano & & & & $x$ \\
\hline & $\begin{array}{l}\text { Resultados e auxílio na condução do } \\
\text { experimento }\end{array}$ & & & & $\mathrm{x}$ \\
\hline \multirow{6}{*}{$\begin{array}{l}\text { Questões e } \\
\text { Exercícios }\end{array}$} & $\begin{array}{lll}\begin{array}{l}\text { Relação com } \\
\text { apresentado }\end{array} & \text { conteúdo } \\
\end{array}$ & & & & $\mathrm{x}$ \\
\hline & $\begin{array}{l}\text { Estímulo à } \quad \text { aplicação } \\
\text { contextualizada com o ambiente }\end{array}$ & & & & $\mathrm{x}$ \\
\hline & $\begin{array}{l}\text { Problematização com pesquisas ou } \\
\text { questões ambientais voltados à } \\
\text { Botânica (desmatamento, } \\
\text { queimadas...) }\end{array}$ & & & & $\mathrm{x}$ \\
\hline & Contextualização com o Cotidiano & & & & $x$ \\
\hline & Respostas no livro do professor & & & & $x$ \\
\hline & $\begin{array}{l}\text { Presença de questões relacionadas } \\
\text { a conteúdos extras }\end{array}$ & & & & $\mathrm{x}$ \\
\hline \multirow{6}{*}{$\begin{array}{l}\text { Conhecimen } \\
\text { to Extra }\end{array}$} & Etnobotânica e plantas medicinais & & & & $\mathrm{x}$ \\
\hline & Plantas alimentícias & & & & $\mathrm{x}$ \\
\hline & $\begin{array}{l}\text { Uso de plantas na indústria } \\
\text { (cosméticos, farmacologia) }\end{array}$ & & & $\mathrm{x}$ & \\
\hline & Paleobotânica & $\mathrm{x}$ & & & \\
\hline & $\begin{array}{l}\text { Mídias extras sobre Botânica (sites, } \\
\text { livros, músicas e outros) }\end{array}$ & & & & $\mathrm{x}$ \\
\hline & Estudos científicos na Botânica & & & & $x$ \\
\hline \multicolumn{2}{|r|}{ Porcentagem da avaliação } & $4 \%$ & $8 \%$ & $12 \%$ & $76 \%$ \\
\hline
\end{tabular}

Fonte: Dados da Pesquisa. 
Quadro 5 - Avaliação do livro didático Para Viver Juntos: Ciências da Natureza (2015) - Livro B

\begin{tabular}{|c|c|c|c|c|c|}
\hline \multicolumn{2}{|r|}{ Critérios } & Ruim & Regular & Bom & Ótimo \\
\hline \multirow{6}{*}{ Conteúdos } & Clareza conceitual & & & & $\mathrm{x}$ \\
\hline & Generalização & & & & $x$ \\
\hline & Coerência & & & & $\mathrm{x}$ \\
\hline & Simplificações & & & & $\mathrm{x}$ \\
\hline & Adequação ao ano escolar & & & $x$ & \\
\hline & Atualização de termos & & & & $x$ \\
\hline \multirow{4}{*}{ Visual } & Ordenação sistemática & & & & $\mathrm{x}$ \\
\hline & Contextualização & & & & $x$ \\
\hline & Organização & & & & $x$ \\
\hline & Fotos, Figuras e Esquemas & & & $x$ & \\
\hline \multirow{4}{*}{ Práticas } & Práticas dentro do meio escolar & & & & $x$ \\
\hline & Práticas fora do ambiente escolar & & & & $x$ \\
\hline & Percepção da Botânica no cotidiano & & & & $\mathrm{x}$ \\
\hline & $\begin{array}{l}\text { Resultados e auxílio na condução do } \\
\text { experimento }\end{array}$ & & & & $\mathrm{x}$ \\
\hline \multirow{6}{*}{$\begin{array}{l}\text { Questões } \\
\text { e } \\
\text { Exercícios }\end{array}$} & Relação com o conteúdo apresentado & & & & $\mathrm{x}$ \\
\hline & $\begin{array}{l}\text { Estímulo à aplicação contextualizada com o } \\
\text { ambiente }\end{array}$ & & & & $\mathrm{x}$ \\
\hline & $\begin{array}{l}\text { Problematização com pesquisas ou questões } \\
\text { ambientais voltados à Botânica (desmatamento, }\end{array}$ & & & $\mathrm{x}$ & \\
\hline & Contextualização com o Cotidiano & & & & $\mathrm{x}$ \\
\hline & Respostas no livro do professor & & & & $\mathrm{x}$ \\
\hline & $\begin{array}{l}\text { Presença de questões relacionadas a conteúdos } \\
\text { extras }\end{array}$ & & & & $x$ \\
\hline \multirow{6}{*}{$\begin{array}{l}\text { Conhecime } \\
\text { nto Extra }\end{array}$} & Etnobotânica e plantas medicinais & & & & $x$ \\
\hline & Plantas alimentícias & & & & $\mathrm{x}$ \\
\hline & $\begin{array}{l}\text { Uso de plantas na indústria (cosméticos, } \\
\text { farmacologia) }\end{array}$ & & $\mathrm{x}$ & & \\
\hline & Paleobotânica & & & & $x$ \\
\hline & $\begin{array}{l}\text { Mídias extras sobre Botânica (sites, livros, } \\
\text { músicas...) }\end{array}$ & & & & $x$ \\
\hline & Estudos científicos na Botânica & & & & $\mathrm{x}$ \\
\hline \multicolumn{2}{|c|}{ Porcentagem da avaliação } & $0 \%$ & $4 \%$ & $12 \%$ & $84 \%$ \\
\hline
\end{tabular}

Fonte: Dados da Pesquisa. 
Quadro 6 - Avaliação do livro didático Ciências (2015) - Livro C

\begin{tabular}{|c|c|c|c|c|c|}
\hline \multicolumn{2}{|r|}{ Critérios } & Ruim & Regular & Bom & Ótimo \\
\hline \multirow{6}{*}{ Conteúdos } & Clareza conceitual & & & & $x$ \\
\hline & Generalização & & & & $x$ \\
\hline & Coerência & & & & $x$ \\
\hline & Simplificações & & & & $\mathrm{x}$ \\
\hline & Adequação ao ano escolar & & & & $x$ \\
\hline & Atualização de termos & & & & $x$ \\
\hline \multirow{4}{*}{ Visual } & Ordenação sistemática & & & & $x$ \\
\hline & Contextualização & & & & $x$ \\
\hline & Organização & & & & $x$ \\
\hline & Fotos, Figuras e Esquemas & & & & $x$ \\
\hline \multirow{4}{*}{ Práticas } & Práticas dentro do meio escolar & & $x$ & & \\
\hline & Práticas fora do ambiente escolar & $x$ & & & \\
\hline & Percepção da Botânica no cotidiano & & & $x$ & \\
\hline & $\begin{array}{l}\text { Resultados e auxílio na condução do } \\
\text { experimento }\end{array}$ & & & & $x$ \\
\hline \multirow{6}{*}{$\begin{array}{l}\text { Questões e } \\
\text { Exercícios }\end{array}$} & Relação com o conteúdo apresentado & & & & $x$ \\
\hline & $\begin{array}{l}\text { Estímulo à aplicação contextualizada } \\
\text { com o ambiente }\end{array}$ & & & & $\mathrm{x}$ \\
\hline & $\begin{array}{l}\text { Problematização com pesquisas ou } \\
\text { questões ambientais voltados à Botânica } \\
\text { (desmatamento, queimadas...) }\end{array}$ & & & $\mathrm{X}$ & \\
\hline & Contextualização com o Cotidiano & & & & $x$ \\
\hline & Respostas no livro do professor & & & & $x$ \\
\hline & $\begin{array}{l}\text { Presença de questões relacionadas a } \\
\text { conteúdos extras }\end{array}$ & & & $x$ & \\
\hline \multirow{6}{*}{$\begin{array}{l}\text { Conhecimento } \\
\text { Extra }\end{array}$} & Etnobotânica e plantas medicinais & & $x$ & & \\
\hline & Plantas alimentícias & & & & $x$ \\
\hline & $\begin{array}{l}\text { Uso de plantas na indústria (cosméticos, } \\
\text { farmacologia) }\end{array}$ & & $\mathrm{x}$ & & \\
\hline & Paleobotânica & & & $x$ & \\
\hline & $\begin{array}{l}\text { Mídias extras sobre Botânica (sites, } \\
\text { livros, músicas...) }\end{array}$ & & $x$ & & \\
\hline & Estudos científicos na Botânica & & $x$ & & \\
\hline \multicolumn{2}{|c|}{ Porcentagem da avaliação total } & $4 \%$ & $19 \%$ & $15 \%$ & $62 \%$ \\
\hline
\end{tabular}

Fonte: Dados da Pesquisa. 
Quadro 7 - Avaliação do livro didático Ciências - Projeto Teláris (2015) - Livro D

\begin{tabular}{|c|c|c|c|c|c|}
\hline \multicolumn{2}{|r|}{ Critérios } & Ruim & Regular & Bom & Ótimo \\
\hline \multirow{6}{*}{ Conteúdos } & Clareza conceitual & & & $\mathrm{x}$ & \\
\hline & Generalização & & $\mathrm{x}$ & & \\
\hline & Coerência & & & & $\mathrm{x}$ \\
\hline & Simplificações & & $\mathrm{x}$ & & \\
\hline & Adequação ao ano escolar & & & & $x$ \\
\hline & Atualização de termos & & $\mathrm{x}$ & & \\
\hline \multirow{4}{*}{ Visual } & Ordenação sistemática & & & $x$ & \\
\hline & Contextualização & & & & $\mathrm{x}$ \\
\hline & Organização & & & & $x$ \\
\hline & Fotos, Figuras e Esquemas & & $\mathrm{x}$ & & \\
\hline \multirow{4}{*}{ Práticas } & Práticas dentro do meio escolar & & & & $x$ \\
\hline & Práticas fora do ambiente escolar & & & & $\mathrm{x}$ \\
\hline & Percepção da Botânica no cotidiano & & & & $\mathrm{x}$ \\
\hline & $\begin{array}{l}\text { Resultados e auxílio na condução do } \\
\text { experimento }\end{array}$ & & & & $\mathrm{x}$ \\
\hline \multirow{6}{*}{$\begin{array}{l}\text { Questões e } \\
\text { Exercícios }\end{array}$} & Relação com o conteúdo apresentado & & & & $\mathrm{x}$ \\
\hline & $\begin{array}{l}\text { Estímulo à aplicação contextualizada } \\
\text { com o ambiente }\end{array}$ & & & & $\mathrm{x}$ \\
\hline & $\begin{array}{l}\text { Problematização com pesquisas ou } \\
\text { questões ambientais voltados à } \\
\text { Botânica } \\
\text { queimadas...) }\end{array}$ & & & & $\mathrm{x}$ \\
\hline & Contextualização com o Cotidiano & & & $x$ & \\
\hline & Respostas no livro do professor & & & & $\mathrm{x}$ \\
\hline & $\begin{array}{l}\text { Presença de questões relacionadas a } \\
\text { conteúdos extras }\end{array}$ & & & $\mathrm{x}$ & \\
\hline \multirow{6}{*}{$\begin{array}{l}\text { Conhecimento } \\
\text { Extra }\end{array}$} & Etnobotânica e plantas medicinais & $x$ & & & \\
\hline & Plantas alimentícias & & & & $x$ \\
\hline & $\begin{array}{l}\text { Uso de plantas na indústria } \\
\text { (cosméticos, farmacologia) }\end{array}$ & $\mathrm{x}$ & & & \\
\hline & Paleobotânica & & $\mathrm{x}$ & & \\
\hline & $\begin{array}{l}\text { Mídias extras sobre Botânica (sites, } \\
\text { livros, músicas...) }\end{array}$ & & & $\mathrm{x}$ & \\
\hline & Estudos científicos na Botânica & & & $\mathrm{x}$ & \\
\hline \multicolumn{2}{|c|}{ Porcentagem da avaliação total } & $8 \%$ & $19 \%$ & $23 \%$ & $50 \%$ \\
\hline
\end{tabular}

Fonte: Dados da Pesquisa.

\section{Análise do conteúdo}

A introdução dos conteúdos de Biologia Vegetal foi disposta num pequeno texto apresentando os principais grupos, e nos livros A, B e D, havia questões iniciais que estimulam os 
alunos a pensarem em seus conhecimentos primários sobre a Botânica. Destaca-se que os livros A e B retomam essas questões ao final do capítulo e questionam o discente se as preconcepções dele mudaram.

Os Livros $A$ e $D$ trabalham o grupo das briófitas dando apenas o exemplo dos musgos, com uma explicação rasa e errônea sobre o grupo, pois definem, "são plantas que vivem em ambientes terrestres e em lugares úmidos", este tipo de afirmação unifica estas características a todos os indivíduos deste grupo. Entretanto, segundo Raven, Evert e Eichhorn (2014), muitas espécies de musgos são encontradas em desertos relativamente secos e outras formam extensos tapetes sobre rochas expostas que podem se tornar muito quentes. Dessa forma, não se pode afirmar que todos os indivíduos possuem essas características. Nos demais livros aparecem mais de um exemplo de briófitas com imagem ilustrativa e a definição do grupo é explicada considerando as exceções descritas na citação acima. Ainda no tema briófitas, foi possível perceber uma possível má interpretação no Livro A na seguinte frase: "as pequenas plantas que formam os musgos [...]", dando a entender que o musgo é o conjunto de plantas e não cada indivíduo. Outra observação é que o livro trata o ciclo reprodutivo como "reprodução dos musgos", ignorando os demais grupos pertencentes a este grupo.

Durante a apresentação do grupo das pteridófitas, foi possível se deparar com simplificações muito semelhantes às encontradas no grupo das briófitas; com definição simplista e o ciclo reprodutivo do grupo pouco detalhado. Destaca-se o Livro B ao adicionar um ciclo rico em informações, com explicações em cada fase do ciclo e demonstrado a separação entre as fases sexuada e assexuada. Além disso, encontra-se nesse livro uma riqueza de exemplos de membros do grupo.

O tema gimnospermas apareceu mais bem estruturado na maior parte dos livros avaliados e, apenas no livro D, o assunto foi trabalhado de forma simplista. No grupo das angiospermas, percebeu-se um erro no Livro A ao trabalhar com a nomenclatura "dicotiledôneas", pois de acordo com Raven, Evert e Eichhorn (2014), antigamente essas plantas eram agrupadas com as eudicotiledôneas como dicotiledôneas. Porém, sabe-se que esse é um sistema artificial de classificação que, simplesmente, salienta as diferenças das monocotiledôneas das demais angiospermas, sendo então as dicotiledôneas um pequeno grupo de plantas arcaicas que possuem o pólen monoaperturado ou alguma modificação deste tipo. Os demais tratam as sementes como "um cotilédone e dois cotilédones" ou com a nomenclatura "eudicotiledôneas". Destaca-se o livro C, ao explicar as três classificações de forma correta.

Tanto o Livro B quanto o A trabalham com a filogenia evolutiva dos grupos das plantas no 
tema angiospermas. Contudo, o livro A utiliza um quadro comparativo entre os grupos de vegetais com presença e ausência de características e o livro B usa um cladograma com a relação evolutiva das plantas. O Livro B ainda mostra em seu texto uma discussão sobre a origem deste grupo com imagens de fósseis.

Na parte dos órgãos vegetativos e reprodutivos o Livro B foi o que apresentou maior número de exemplos com imagens e textos explicativos coerentes. Nos livros $C$ e $D$ há um menor número de exemplos e algumas falhas chamaram atenção e merecem ser citadas. Nenhum deles abordou as raízes axial e fasciculada, e sabe-se que é a partir destas que se formam os demais morfotipos de raízes. Além disso, o livro $D$ foi o único que não listou as partes da raiz, trabalhando este conteúdo de forma simplista e má organizada.

O Caule é abordado na maior parte dos livros a partir da explicação das suas partes, função e tipos de caule. Entretanto, no livro D, assim como no tema raiz, não se trabalham as partes do caule. O conteúdo referente a folhas, de forma geral, compreende fotossíntese, respiração e transpiração, além das partes da folha, estômatos e tipos de modificações foliares. Os órgãos reprodutivos das plantas apareceram nos livros com maior riqueza de detalhes, todos abordam as regiões das flores e das sementes, explicam de forma coerente como a partir da reprodução são formados os frutos e onde se encontram as sementes, além dos vários tipos de frutos e a importância das relações ecológicas com os animais para a polinização e dispersão, junto de outros elementos, como o vento e a água.

\section{Análise do visual}

Em relação ao visual dos livros analisados, infere-se que nos livros C e D as imagens são maiores, assim como o tamanho da fonte das letras. Já nos livros A e B tende a ser o contrário, imagens menores e letras com fonte menor. Entretanto, percebe-se que no livro $\mathrm{B}$ há um maior número de imagens e diversidade, provavelmente a fim de trazer maior número de figuras, e assim escolheram dispô-las em escala menor. De acordo com Martins, Gouvêa e Piccinini (2005), nas últimas séries do fundamental, passa a ser mais evidente a manipulação de elementos composicionais, tais como cor e escala, e a consequente necessidade de seu entendimento para a significação das entidades representadas. A presença de fonte das imagens aparece em todos os livros, já as escalas são presentes nos livros A, B e C. Sabe-se que as escalas permitem ao aluno reconhecer o tamanho real daqueles exemplares, dando a ele maior noção de como são essas plantas em seu verdadeiro tamanho na natureza (Figura 01). 
Segundo Silva et al. (2006), o uso de imagens constitui parte fundamental das práticas de ensino. Há um consenso entre vários autores sobre o fato de as imagens desempenharem importante papel pedagógico no processo de ensino-aprendizagem. O Livro A se destacou ao realçar a coloração das páginas com as imagens, chamando mais atenção aos exemplos ali descritos. Já no livro D, percebese que a coloração das letras e ilustrações são um pouco apagadas. Segundo Neto e Fracalanza (2003), as deficiências gráficas, a qualidade inadequada do papel ou uma diagramação cansativa são problemas encontrados nos Livros Didáticos, como visto na Figura 1.

Figura 1 - Análise dos recursos visuais dos livros investigados (livros A, B, C e D, respectivamente)

A

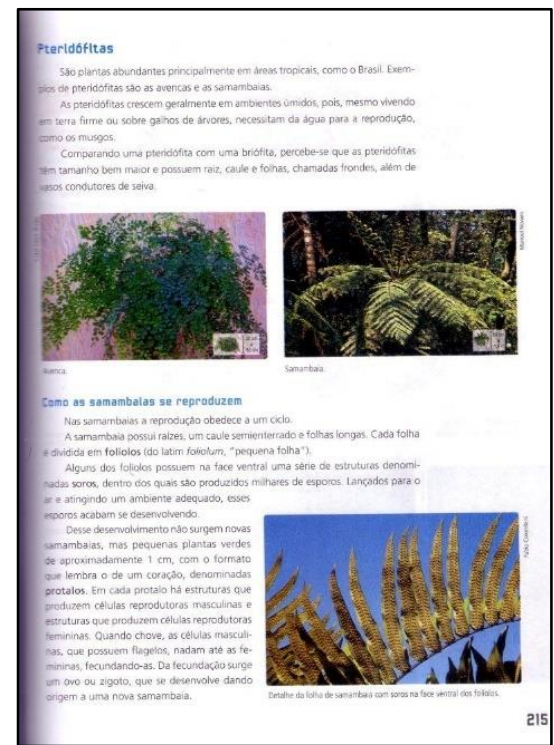

C

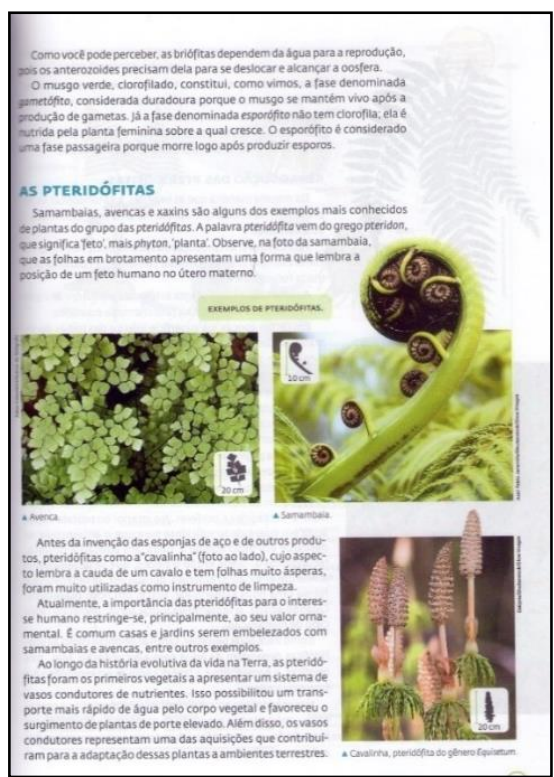

B

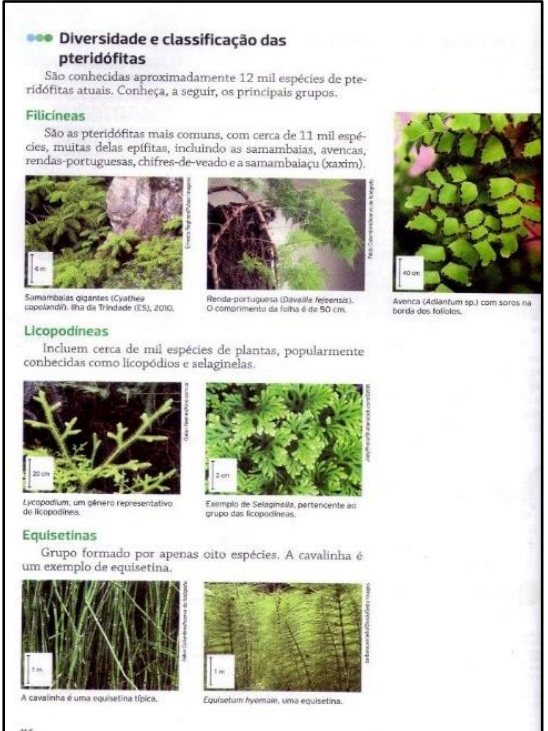

D

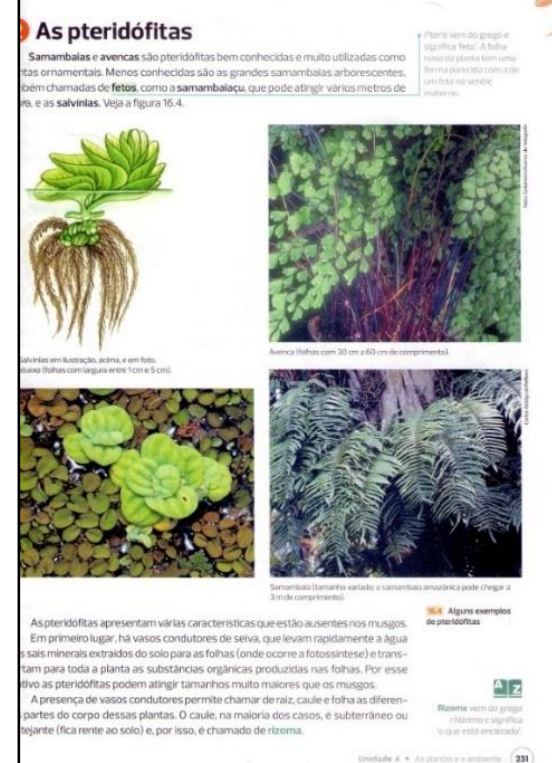

Fonte: Gowdak e Martins (2015, p. 215), Aguilar (2015, p. 116), Barros e Paulino (2015, p. 1110) e 
Gewandsznajder (2015, p. 231).

Ainda, aponta-se o livro D, em que há uma imagem com a legenda "observam-se células cheias de clorofilas em microscópio de luz". Entretanto, o que se observa na imagem são cloroplastos e não clorofilas (Figura 2A). Outro erro percebido no mesmo livro refere-se a uma imagem sobre as salvinias, um grupo de pteridófitas aquáticas. Porém, o foco de uma das fotografias da imagem está sobre uma "alface d'água" que é uma angiosperma, causando nos alunos uma percepção errônea sobre a planta a qual se trata (Figura 2B).

Figura 2 A e B - Erros encontrados em imagens/Legendas de Imagens (livro D)
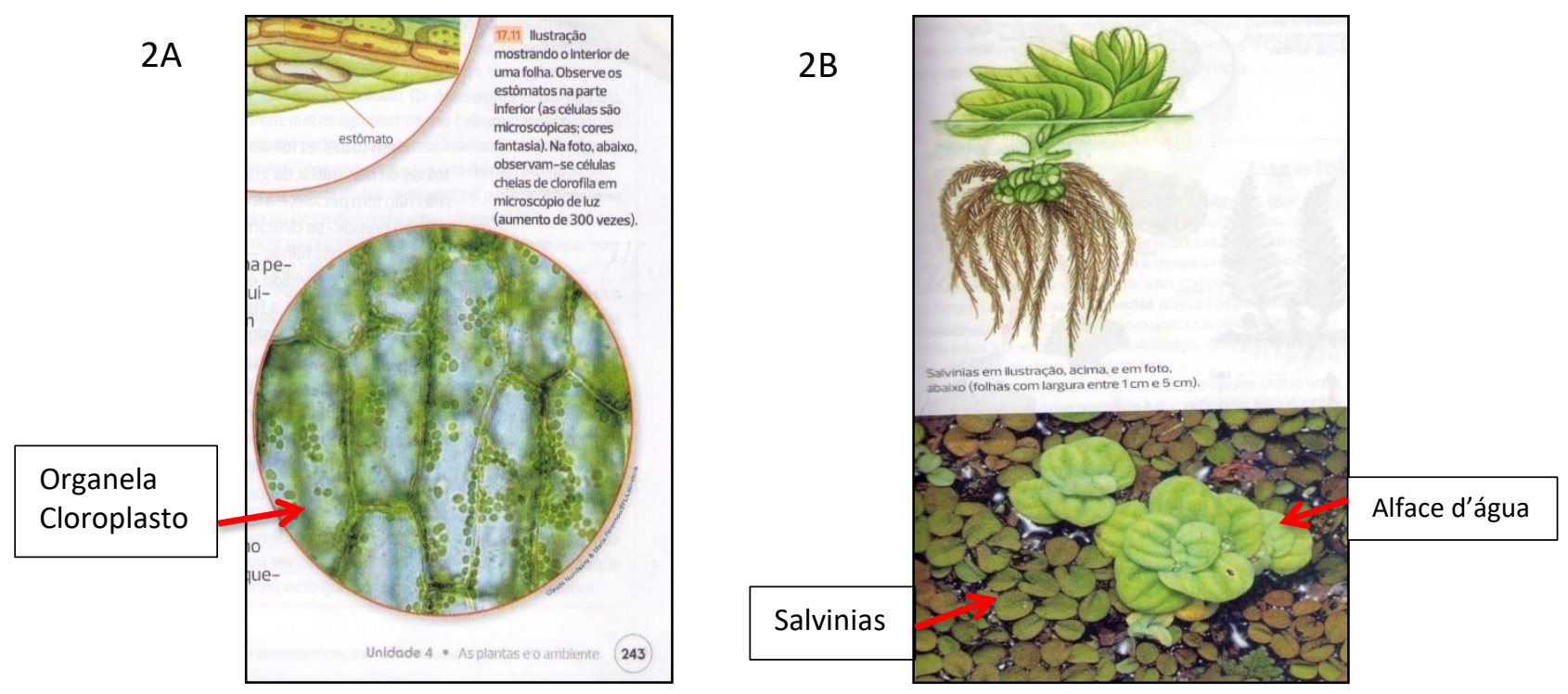

Fonte: Gewandsznajder (2015, p. 231 e 243)

\section{Análise das atividades práticas}

O Livro B complementa o tema com um experimento "Ciência a mão". Nessa parte do livro há uma experiência para germinação de soros de samambaia. Durante todo o processo há dicas ao professor para auxiliá-lo durante a execução da prática. Sprigol e Giannotti (2008) perceberam em seu trabalho que as práticas possibilitaram criatividade, desinibição e participação dos alunos e fizeram com que se sentissem motivados, envolvidos com a problemática o que, consequentemente, facilitou a reflexão e a significação do tema abordado. Há ainda, no livro $B$, um experimento de germinação de sementes e uma prática para que os alunos criem um viveiro de mudas na escola.

Carvalho (2004) diz que se deve incluir no ensino de ciências, ideias construtivistas para uma aprendizagem significativa dos conhecimentos científicos, pois esta requer a participação dos 
estudantes na (re)construção dos conhecimentos, que habitualmente se transmitem já elaborados, e superar os reducionismos e visões deformadas na natureza das ciências. Dessa forma, é compreensível a necessidade da introdução de práticas que possibilitem a participação dos alunos dentro do processo de ensino, potencializando a aprendizagem dos mesmos.

No Livro B há uma prática de percepção das plantas do dia a dia por meio do uso de fotografias e o aluno deve elaborar um portfólio e apresentar para os demais discentes da turma. Segundo Silva (2008), as aulas no ambiente natural devem ser consideradas importantes, inclusive porque permitem que se conheçam os seres vivos, de forma que sua função, causa e o que representam estejam vinculados, ou seja, que sejam vistos com um todo, o que tem sido comumente desconsiderado no ensino atual da Botânica, colaborando para um ensino fragmentado.

No livro A há duas experiências sobre estômatos e transpiração das folhas, com metodologia bem-feita e imagem explicativa. Nos livros $C$ e $D$ há poucas ou apenas uma prática. No primeiro há um experimento sobre a transpiração das folhas extremamente breve e com pouco destaque, e no outro encontra-se uma prática com o uso de materiais pouco comuns na rede pública, o microscópio. De acordo com o Instituto Nacional de Estudos e Pesquisas (Inep), no ano de 2015, menos de 5\% das escolas do ensino fundamental possuíam infraestrutura e acessibilidade adequada no país. Dessa forma, seria pouco viável a execução de práticas com o uso de microscópios na rede pública.

\section{Análise das questões e exercícios}

Em todos os livros aparecem questões de localização referentes ao conteúdo apresentado, que auxiliam na confirmação do aprendizado das informações presentes nos textos do capítulo e questões que os auxiliam em reflexões mais elaboradas acerca do tema, como Botânica aplicada, questões problematizadoras, que estimulam o senso crítico e o pensamento científico no aluno. Destacam-se os livros B e D, que trabalham com maestria nesses quesitos, estimulando os alunos a elaborar um cardápio com as partes do corpo de angiospermas, perguntas sobre as necessidades minerais das plantas, vantagens adaptativas, entre outras. De acordo com Moraes (2008), é necessário levar o indivíduo a aprender a aprender, que se manifesta pela capacidade de refletir, analisar e tomar consciência do que sabe, dispor-se a mudar os próprios conceitos, buscar novas informações, substituir velhas "verdades" por teorias transitórias, adquirir os novos conhecimentos que vêm sendo requeridos pelas alterações existentes no mundo, resultantes da rápida evolução das tecnologias da informação.

Foi observada no livro C uma metodologia não presente nos demais, chamada "mapa de 
conceitos". Segundo Moreira (2005), mapas conceituais são diagramas indicando relações entre conceitos e podem seguir um modelo hierárquico no qual conceitos mais inclusivos estão no topo da hierarquia (parte superior do mapa) e conceitos específicos, pouco abrangentes, estão na base (parte inferior). Nesse livro, essa metodologia foi utilizada como um resumo/atividade com palavras-chave relacionadas aos conteúdos aprendidos e os alunos deveriam complementar as palavras que faltavam com as dispostas no "banco de palavras", como observado na figura 03.

Figura 3 - Mapa de conceitos do livro Ciências (Livro C)

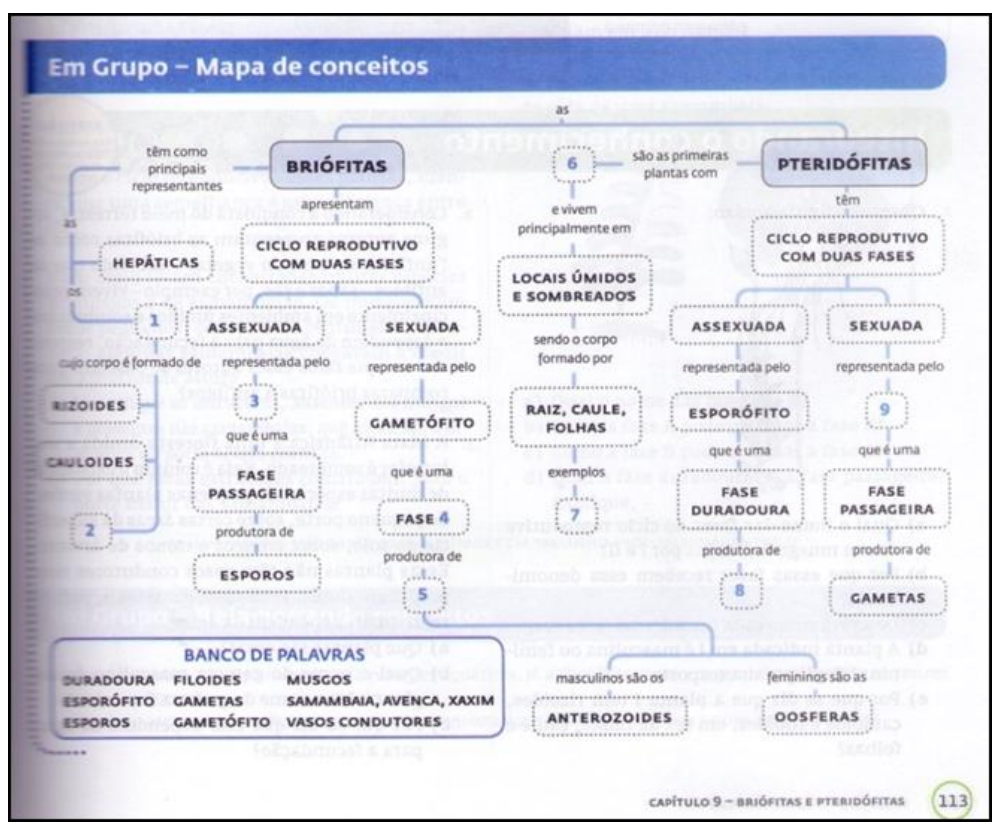

Fonte: Barros e Paulino (2015, p. 113)

\section{Análise de conhecimento extra}

Nos livros B e C trabalha-se com um texto sobre o registro fóssil de pteridófitas durante o Carbonífero, e possuem ilustrações que recriam o possível ambiente daquela época. Conforme Martins, Gouvêa e Piccinini (2005), os livros passam a incluir localidades e tempos remotos, alguns sem correspondência no cotidiano do aluno que permitam a ampliação da noção de tempo e espaço por parte do estudante.

O Livro C apresenta exemplos com imagens grandes de plantas exóticas e nativas em junção com um texto complementar "Araucárias e pinhões" que aborda temas como alimentação, desmatamento e relação com animais. No Livro A há um texto complementar sobre a "importância do pinhão", abrangendo a importância nutritiva, econômica e sociocultural unido a atividades pertinentes ao assunto. Já o Livro B apresenta dois textos "Uso das gimnospermas pelo ser humano" que faz 
menção do uso do óleo essencial e de sua função bactericida e também aborda o uso cultural dentro de civilizações antigas como egípcios e gregos e o texto externo "Araucária", que trata a conservação e ameaças de extinção do pinheiro-do-paraná.

O livro A apresenta um texto retirado de artigo "raiz de planta é usada para criar bateria ecológica". Esse texto faz divulgação científica para o ensino básico e permite aos alunos descobrir novas utilidades dentro do grupo das plantas. Segundo Albagli (1996), o papel da divulgação científica vem evoluindo ao longo do tempo e trata de transmitir informação científica tanto com um caráter prático, com o objetivo de esclarecer os indivíduos sobre o desvendamento e a solução de problemas relacionados a fenômenos já cientificamente estudados, quanto com um caráter cultural, visando a estimular-Ihes a curiosidade científica enquanto atributo humano.

O livro B apresenta um texto complementar "palmito em extinção" sobre a extração das palmeiras na Mata Atlântica. O livro D trabalha um texto sobre plantas transgênicas e apresenta a importância e os impactos do uso desses alimentos. Há uma variedade de formas com que o educador poderia trabalhar com esse texto, no entanto, não há indicações disto para o professor; o próprio texto poderia ter questões que instigassem os alunos.

Os livros A e D apresentam textos complementares referentes à reprodução das bananeiras. No livro B são trabalhados outros três textos interessantes que aparecem sobre os assuntos "crédito de carbono", "cuidar de jardins e hortas protege os mais velhos do Alzheimer" e "professora fala sobre o uso correto de plantas medicinais". São textos atuais e didáticos que levam à reflexão e possuem questões que estimulam os alunos. O Livro D utiliza o texto complementar "luz e fotossíntese" no final do capítulo. É um texto interessante, contudo, seria mais didático se estivesse em um livro do 9o ano, visto que seu foco estava em tratar do assunto "Luz".

No livro A há o texto "oito plantas tóxicas comuns do Brasil" que trabalha com plantas muito comuns e que muitos alunos já poderiam ter tido contato anterior, estudando suas partes tóxicas e os efeitos e prevenções caso entrem em contato com elas. Vasconcelos, Vieira e Vieira (2009) justificam a importância de se divulgar o assunto "plantas tóxicas", pois é sabido que a intoxicação por plantas acontece geralmente por desconhecimento do potencial tóxico das espécies.

As mídias externas são requisitos do PNLD e aparecem em todos os livros, mas a diferença de abordagem é perceptível: nos livros A, C e D há um pequeno quadro ao fim de cada capítulo que traz apenas o link ou nome do referencial (livro C), ou o referencial com uma breve explicação do que trata o conteúdo extra ali apresentado (Livros A e D). Entretanto, o livro B dedica uma página inteira 
para apresentações de livros e sites, com descrição mais elaborada a cada uma das propostas.

\section{Considerações Finais}

Como norteadores do ensino-aprendizagem de grande parte da população nacional, os livros didáticos devem se comprometer não apenas em disponibilizar o conteúdo em forma de textos, mas também utilizar imagens, fontes extras, práticas e exercícios, tanto de fixação quanto de reflexão e contextualização. Percebe-se que algumas obras utilizam termos que podem causar problemas de interpretação entre os leitores, desta forma, o professor, que não se mantém atento e atualizado ao ministrar esse conteúdo, pode cair no erro de passar notícias incorretas e/ou ambíguas aos seus discentes.

Além disso, também foi possível detectar alguns erros de conteúdos e de imagens em algumas obras. Entretanto, há uma gama de exercícios e experimentos que estimulam a percepção do ambiente natural, colaborando para um ensino sistemático e, principalmente, contextualizado com o cotidiano dos educandos.

O visual das obras analisadas é em sua maioria de boa qualidade, assim como a organização entre os conteúdos, sendo poucas as exceções que necessitam de revisão. De forma geral, nota-se que as obras aqui analisadas possuem componentes interessantes e enriquecedores para o ensino de Botânica. Contudo, o professor não deve se abster de lecionar esse conteúdo com riqueza de metodologias.

A Botânica, acima de tudo, está presente na alimentação, cosméticos, mobília, livros, borracha e diversos outros materiais da vida cotidiana. Muitos são os usos das plantas feitos pelo homem, e sabe-se que a vegetação se apresenta de fácil acesso na maior parte do país. Dessa forma, cabe ao educador levar em consideração o uso de outros recursos pedagógicos para o ensino de Botânica, para despertar o interesse dos alunos, e principalmente o gosto em aprender sobre as questões que cercam o reino vegetal. Em suma, as análises aqui discutidas não elegem um livro melhor que outro, mas estabelecem críticas e elogios dentro dos conteúdos avaliados. Espera-se que a partir delas sejam elaborados conteúdos mais aprofundados e contextualizados para uma melhora significativa do ensino de Botânica no país. 


\section{Referências}

AGUILAR, J. B. Para viver juntos: ciências da natureza 7o ano. 4. ed. São Paulo: Edições SM, 2015.

ALBAGLI, S. Divulgação científica: informação científica para cidadania. Ciência da informação, v. 25, n. 3, p. 396-404, 1996.

BANDEIRA, A.; STANGE, C. E. B.; SANTOS, J. M. T. Uma proposta de critérios para análise de livros didáticos de ciências naturais na educação básica. In: III SIMPÓSIO NACIONAL DE ENSINO DE CIÊNCIA E TECNOLOGIA, 2012, Ponta Grossa. Anais eletrônicos... Disponível em: <http://www.sinect.com.br/anais2012/html/artigos/ensino\%20cie/6.pdf $>$. Acesso em: 11 fev. 2017.

BARROS, C.; PAULINO, W. Ciências 70 ano. 6. ed. São Paulo: Ática, 2015.

BRASIL. Ministério da Educação. Fundo Nacional do Desenvolvimento da Educação. Brasília, DF: MEC, 2017. Disponível em: <http://www.fnde.gov.br/programas/livro-didatico $>$. Acesso em: 11 fev. 2017.

CARNEIRO, M. H. S.; SANTOS, W. L. P.; MÓL, G. S. Livro didático inovador e professores: uma tensão a ser vencida. Ensaio: Pesquisa em Educação e Ciências. Belo Horizonte, v. 7, n. 2, p. 101-113, 2005.

CARVALHO, A. M. P. Ensino de Ciências: unindo a pesquisa e a prática. São Paulo: Cengage Learning Editores, 2004.

DEMO, P. Educar pela pesquisa. 7. ed. Campinas: Autores Associados, 2005.

GEWANDSZNAJDER, F. Projeto Teláris, Ciências 7o ano. 2. ed. São Paulo: Ática, 2015.

GOWDAK, D. O.; MARTINS, E. L. Ciências Novo Pensar 7o ano. 2. ed. São Paulo: FTD, 2015.

GUIA DO LIVRO DIDÁTICO. Disponível em: <http://www.fnde.gov.br/pnld-2017/>. Acesso em: 23 fev. 2017.

INSTITUTO NACIONAL DE ESTUDOS E PESQUISAS EDUCACIONAIS ANÍSIO TEIXEIRA (Inep). Infraestrutura. Disponível em: <http://www.observatoriodopne.org.br/metas-pne/7-aprendizadoadequado-fluxo-adequado/estrategias/7-18-infraestrutura/indicadores\#de-escolas-do-ensinofundamental-com-infraestrutura-adequada> Acesso em: 23 fev. 2017.

LOPES, J. L. et al. Escala de diferencial semântico para avaliação da percepção de pacientes hospitalizados frente ao banho. Acta Paul Enferm, v. 24, n. 6, p. 815-20, 2011.

MARTINS, I.; GOUVÊA, G.; PICCININI, C. Aprendendo com imagens. Ciência e Cultura, Campinas, v. 57, n. 4, p. 38-40, 2005.

MELO, E. A. et al. A aprendizagem de Botânica no ensino fundamental: Dificuldades e desafios. Scientia plena. Aracaju, v. 8, n. 10, p. 1-8, 2012.

MORAES, M. C. O paradigma educacional emergente: implicações na formação do professor e nas práticas pedagógicas. Em Aberto, Brasília-DF, v. 16, n. 70, p. 57-69, 2008.

MOREIRA, M. A. Mapas conceituais e aprendizagem significativa. Revista Chilena de Educação Científica, Chile, v. 4, n. 2, p. 38-44, 2005.

NETO, J. M.; FRACALANZA, H. O livro didático de ciências: problemas e soluções. Ciência \& Educação, Bauru, v. 9, n. 2, p. 147-157, 2003. 
RAVEN, P. H.; EVERT, R. F.; EICHHORN, S. E. Biologia Vegetal. 8. ed. Rio de Janeiro: Guanabara Koogan, 2014.

SILVA, H. C. et al. Cautela ao usar imagens em aulas de ciências. Ciência \& Educação, Bauru, v. 12, n. 2, p. 219-233, 2006.

SILVA, J. N.; LOPES, N. P. G. Botânica no Ensino Fundamental: diagnósticos de dificuldades no ensino e da percepção e representação da biodiversidade vegetal por estudantes. Revista Electrónica de Enseñanza de las Ciencias, v. 13, n. 2, p. 115-136, 2014. Disponível em: <http://reec.uvigo.es/volumenes/volumen13/REEC 13221 ex773.pdf>. Acesso em 05 out. 2017.

SILVA, P. G. P. O ensino da Botânica no nível fundamental: um enfoque nos procedimentos metodológicos. 2008. 146 f. Tese (Doutorado em Ciências) - Universidade Estadual Paulista. Faculdade de Ciências, Bauru, 2008.

SPRIGOL, S.; GIANNOTTI, S. M. A importância da utilização de práticas no processo de ensinoaprendizagem de ciências naturais enfocando a morfologia da flor. In: 10 SIMPÓsıO NACIONAL DE EDUCAÇÃO-XX SEMANA DE PEDAGOGIA, Cascavel. Anais eletrônicos... Cascavel, 2008. Disponível em: http://www.unioeste.br/cursos/cascavel/pedagogia/eventos/2008/1/Artigo\%2033.pdf. Acesso em: 22 nov. 2017.

TATARA, E.; LISOVSKI, L. A. Livro didático de ciências: o início de seu processo de avaliação no Brasil. In: 6o ENCONTRO DE PRODUÇÃo CIENTíFICA E TECNOLÓGICA, Anais eletrônicos... 2011. p. 1-11. Disponível em: http://www.fecilcam.br/nupem/anais vi epct/PDF/ciencias humanas/04 Hum Completo.pdf. Acesso em: 22 nov. 2017.

VASCONCELOS, J.; VIEIRA, J. G. P.; VIEIRA, E. P. P. Plantas tóxicas: conhecer para prevenir. Revista Científica da UFPA, Belém, v. 7, n. 1, p. 1-10, 2009.

VASCONCELOS, S. D.; SOUTO, E. O livro didático de ciências no ensino fundamental: proposta de critérios para análise do conteúdo zoológico. Ciência \& Educação, Bauru, v. 9, n. 1, p. 93-104, 2003.

Recebido em: 18/07/2017 Aceito em: 05/10/2017 